\title{
Pengaruh skill abad 21 terhadap keputusan karir siswa sekolah menengah kerjuruan
}

\author{
Nikmarijal Nikmarijal $^{\left.{ }^{*}\right)}$, Janawi Janawi ${ }^{1}$, Wahyudi Wahyudi ${ }^{1}$, Komariah Komariah ${ }^{1}$ \\ ${ }^{1}$ Institute Agama Islam Negeri Syaikh Abdurrahman Siddik, Bangka Belitung, Indonesia
}

\begin{tabular}{l} 
Article Info \\
\hline Article history: \\
Received Des $10^{\text {th }}, 2021$ \\
Revised Jan $14^{\text {th }}, 2022$ \\
Accepted Jan $27^{\text {th }}, 2022$ \\
\end{tabular}

\section{Keyword:}

Skill Abad 21

Keputusan karir Siswa sekolah menengah kejuruan

\section{Corresponding Author:}

Nikmarijal, N.,

IAIN Syaikh Abdurrahman Siddik Bangka Belitung, Indonesia

Email: nikmarijal@gmail.com

\begin{abstract}
By choosing SMK, it means that students have also chosen what profession they will pursue in the future. The process of choosing a future profession stretches over a long period of time and includes a variety of small choices that eventually lead to a particular professional path. To achieve the desired career in accordance with the demands of today's era, of course mastery of $21 \mathrm{st}$ century skills is needed. Because not all students who graduate from school are ready to work. This research is quantitative descriptive. The instrument used is a Career Choice Decision Making Questionnaire and a 21st Century Skill Ability Questionnaire. Based on Table 1 the significance value output above is known between 21st Century Skills (X) and Career Decisions (Y) the Significance value (Sig, (1-tailed) is .00 which means $<0.05$. So based on this it can be seen clearly that there is a significant correlation.
\end{abstract}

(C) 2022 The Authors. Published by IICET.

This is an open access article under the CC BY-NC-SA license

(https://creativecommons.org/licenses/by-nc-sa/4.0

\section{Pendahuluan}

Tujuan besar pendidikan, mempersiapkan siswa untuk berkontribusi pada dunia kerja dan kehidupan bermasyarakat, telah menjadi salah satu tantangan terbesar abad ini (Bentley, 2012). Begitupun dengan Sekolah Menengah Kejuruan (selanjutnya disingkat SMK) yang merupakan upaya pemerintah untuk menyiapkan tenaga kerja professional yang pada abad 21 ini memiliki tantangan dan peluang yang besar (Tilaar, 1998) Karena pada dasarnya siswa SMK sebagai bagian masyarakat mendambakan kebahagiaan dalam hidupnya. Dalam meraih kebahagiaan tersebut orang terus berusaha semaksimal mungkin mencapai sukses, baik dalam belajar, bekerja, berkeluarga, maupun bermasyarakat. Mereka yang sukses biasanya menyenangi bidang pekerjaan yang digelutinya. Kesuksesan mereka itu diakui oleh teman-temannya dan masyarakat di sekitarnya(Supriatna \& Budiman, 2009).

SMK merupakan salah satu bentuk satuan pendidikan formal yang menyelenggarakan pendidikan kejuruan pada jenjang pendidikan menengah(Indonesia, 2003). Tujuan khusus pendidikan menengah kejuruan adalah sebagai berikut: (a) menyiapkan peserta didik agar menjadi manusia produktif, mampu bekerja mandiri, mengisi lowongan pekerjaan yang ada sebagai tenaga kerja tingkat menengah sesuai dengan kompetensi dalam program keahlian yang dipilihnya; (b) menyiapkan peserta didik agar mampu memilih karir, ulet dan gigih dalam berkompetensi, beradaptasi di lingkungan kerja dan mengembangkan sikap profesional dalam bidang keahlian yang diminatinya; (c) membekali peserta didik dengan ilmu pengetahuan, teknologi dan seni agar mampu mengembangkan diri di kemudian hari baik secara mandiri maupun melalui 
jenjang pendidikan yang lebih tinggi; dan (d) membekali peserta didik dengan kompetensi yang sesuai dengan program keahlian. yang dipilih.

Dengan memilih SMK, berarti siswa juga sudah memilih profesi apa yang akan ditempuh di masa yang akan datang. Proses memilih profesi masa depan terbentang selama jangka waktu yang panjang dan mencakup berbagai pilihan kecil yang akhirnya melalui jalur profesional tertentu. Banyak dari pilihan ini dapat disebut pendidikan, karena termasuk keputusan tentang sekolah, perguruan tinggi, jurusan atau jalur pendidikan lain yang membuka berbagai alternatif profesional dan keputusan(Bubic, 2014). Seperti yang disampaikan oleh super (1980) tentang teori pengembangan karir, pilihan pendidikan mewakili siklus mini pengembangan karir dan membutuhkan keputusan yang nantinya mempengaruhi siklus berikutnya dan pilihan keputusan akhir (Super, 1980).

Pada usia remaja, pikiran tentang karir masa depan biasanya sangat abstrak dan umum, dan anak-anak sering menyebutkan profesi yang terlihat di lingkungan mereka seperti pekerjaan orang tua mereka, fantasi pekerjaan atau pekerjaan yang diterima secara sosial dan spesifik gender(Auger, Blackhurst, \& Wahl, 2005; Gottfredson, 1981; Helwig, 1998; Seligman, Weinstock, \& Owings, 1988; Trice, Hughes, Odom, Woods, \& McClellan, 1995). Anak-anak dan remaja berada pada posisi yang kurang menguntungkan ketika berhadapan dengan peluang untuk mengembangkan identitas karir mereka karena mereka memiliki akses terbatas terhadap model peran karir yang berbeda (Fisher \& Griggs, 1995; Norman C Gysbers, 1996).

Disisi lain Meningkatnya permintaan akan tenaga kerja yang sangat terampil juga berarti bahwa akan ada kesenjangan pendapatan yang meningkat antara pekerja yang kurang berpendidikan, relative tidak terapil dan pekerja berpendidikan tinggi dan sangat terampil. Tugas rutin semakin diotomatisasi dan pekerjaan rutin masih dilakukan oleh orang-orang yang tidak dibayar dengan upah yang layak(Trilling \& Fadel, 2009). Maka untuk memenuhi hal tersebut, keterampilan penting sebagai persyaratan pekerjaan untuk abad 21 adalah 1) kemampuan dengan mudah dan cepat memperoleh dan menerapkan pengetahuan baru, 2) pengetahuan untuk menerapkan keterampilan abad 21 (Osawele \& Uzairue, 2013).

Untuk mencapai karir sesuai yang diinginkan sesuai dengan tuntutan zaman saat ini, tentunya penguasaan skill abad 21 sangat diperlukan. Dikarenakan tidak semua siswa yang lulus sekolah siap untuk bekerja. Hal ini dikarenakan mereka kurang dalam beberapa keterampilan dasar dan sejumlah besar keterampilan terapan : seperti, 1) Komunikasi lisan dan tertulis, 2) pemikiran kritis dan pemecahan masalah, 3) profesionalisme dan etos kerja, 4) kerja tim dan kolaborasi 5) bekerja dengan berbagai tim, 6) menerapkan teknologi, 7) kepemimpinan dan manajemen (Bellanca, 2010)

\section{Metode}

Penelitian ini merupakan penelitian Deskriptif kuantitatif. Populasi dalam penelitian ini adalah Siswa SMK di Kota Pangkal Pinang yang berasal dari SMKN 1 Pangkal Pinang, SMKN 2 Pangkal Pinang, SMKN 3 Pangkal Pinang SMKN 4 Pangkal Pinang, masing berjumlah 10 orang siswa dengan total 40 orang siswa. Dengan Teknik pengambilan sampel dalam penelitian ini adalah teknik non random sampling melalui teknik sampling purposive.

Instrument yang digunakan adalah angket Pengambilan Keputusan Pilihan Karir dan angket kemampuan skill abad 21. Analisis data yang digunakan untuk melihat pengaruh antara skill abad 21 terhadap keputusan karis siswa SMK adalah dengan menggunakan korelasi product moment dari Karl Pearson.

\section{Hasil dan Pembahasan}

Berdasarkan Tabel 1 outpot nilai signifikansi diatas diketahui antara Skill Abad 21 (X) dengan Keputusan Karir (Y) nilai Signifikansi (Sig, (1-tailed) adalah .00 yang berarti $<0,05$. Jadi berdasarkan hal tersebut dapat dilihat dengan jelas bahwa terdapat korelasi yang signifikan.

Skil abad 21 secara garis besar terbagi 3 (tiga) yaitu : 1) Kemampuan belajar dan berinovasi, 2) Kemampuan literasi digital dan 3) Karir dan kecakapan Hidup (Trilling \& Fadel, 2009). 1) Kemampuan Belajar dan berinovasi, 2) Komunikasi dan Kolaborasi, 3) Kreativitas dan Inovasi. Hal ini mempengaruhi keputusan karir Siswa. Kemampuan mengambil keputusan karier merupakan teknik untuk menentukan bidang karier yang paling tepat, yakni bidang karier yang bermakna, baik bagi sendiri, keluarga, maupun lingkungan yang lebih luas. Pengambilan keputusan karir merupakan peristiwa yang selalu terjadi dalam setiap aspek kehidupan manusia. Hal tersebut sebagai konsekuensi dari dinamika perkembangan yang selalu berubah dan sebagai salah satu bentuk respon manusia terhadap lingkungannya. Pengetahuan yang mendasari 
kemampuan membuat keputusan karier adalah pengetahuan mengenai tujuan hidup, diri sendiri, lingkungan, nilai-nilai, dunia kerja, dan pengetahuan tentang keputusan karier. Tujuan hidup siswa sangat dipengaruhi oleh fiosofi yang dijadikan referensi masyarakat tempat ia berada,baik filosofi budaya, agama, maupun kehidupan berbangsa dan bernegara.

Tabel 1. Korelasi Skill abad 21 terhadap Keputusan Karir Siswa SMK

\begin{tabular}{llcc}
\hline & & Skill Abad 21 & Keputusan Karir \\
\hline Skill & Pearson Correlation & 1 & $.868^{* *}$ \\
& Sig. (2-tailed) & & .000 \\
& $\mathrm{~N}$ & 40 & 40 \\
\multirow{4}{*}{ Karir } & Pearson Correlation & $.868^{* *}$ & 1 \\
& Sig. (2-tailed) & .000 & \\
& $\mathrm{~N}$ & 40 & 40 \\
\hline
\end{tabular}

Pengambilan keputusan merupakan upaya untuk membantu individu menyadari semua faktor yang melekat pada pengambilan keputusan sehingga mereka mampu membuat pilihan-pilihan yang didasarkan pada pengetahuan tentang diri dan informasi lingkungan yang sesuai. Kesulitan Pengambilan keputusan karir adalah masalah karir yang paling umum ditemui(Osipow, 1999) dan dapat melibatkan keputusan seperti memilih perguruan tinggi besar, mengubah jalur karir, atau memutuskan kapan untuk pensiun(Bullock-Yowell et al., 2014). Gysbers (1997) menyatakan bahwa sebagian besar anak-anak dan remaja tidak dapat membuat keputusan karir cerdas hanya didasarkan pada pengalaman hidup. Mereka membutuhkan dukungan dan eksplorasi dalam bentuk persembahan kurikulum dan program bimbingan untuk membantu membimbing mereka menuju arah karir(N C Gysbers \& Henderson, 1997).

Mengantisipasi sebuah pilihan merupakan proses mengarahkan individu pada suatu pilihan yang tepat. Tiedeman dan O'Hara membagi antisipasi dalam membuat keputusan menjadi empat proses, 1) Eksplorasi, adalah penjelajahan terhadap kemunkinan alternatif keputusan yang akan diambil. 2) Kristalisasi, merupakan sebuah stabilisasi dari representasi berpikir. Pada tahap kristalisasi, pemikiran dan perasaan mulai terpadu dan teratur. Keyakinan atas pilihan yang akan diambil menguat. Definisi tentang alternatif pilihan emakin jelas. 3) Pemilihan, Sebagaimana perkembangan kristalisasi, pemilihan pun terjadi. Individu percaya atas pilihannya. 4) Klarifikasi Ketika seseorang membuat keputusan lalu ia melakukannya. Dalam perjalanannya mungkin ada yang lancar mungkin ada yang mempertanyakan kembali karena kebingungan. Pada saat kebingunan maka ia seharusnya melakukan eksplorasi kembali, kristalisasi, lalu lakukan pemilihan alternatif kembali dan seterusnya (Supriatna \& Budiman, 2009).

Pentingnya keputusan karir yang diambil siswa SMK, meskipun dalam prosesnya bukanlah hal yang mudah karena individu harus berusaha mengatasi ketidakjelasan mengenai kapabilitasnya, kestabilan minat, prospek alternatif pilihan untuk saat ini dan masa yang akan datang, aksesibilitas karir, dan identitas yang ingin dikembangkan dalam diri mereka sendiri (Bandura, 1997). Hal ini menyebabkan tidak semua remaja dapat dengan mudah mengambil keputusan karir, dan banyak diantara mereka mengalami episode keraguan sebelum mantap pada suatu jalur karir(Creed, Prideaux, \& Patton, 2005). Keraguan tersebut termanifestasikan sebagai kesulitan-kesulitan yang dihadapi individu ketika memutuskan karir(Gati, Krausz, \& Osipow, 1996). Kesulitan-kesulitan ini dapat menjadikan individu menyerahkan tanggung jawab pengambilan keputusan pada orang lain, atau menunda dan menghindar dari tugas mengambil keputusan, yang dapat mengakibatkan pengambilan keputusannya tidak optimal. Tekanan yang dirasakan dapat mempengaruhi beragam aspek kehidupan sehari-hari, cara individu mengambil keputusan akan mempengaruhi caranya mengambil keputusan karir di masa depan(Gati \& Saka, 2001), serta dapat mengakibatkan konsekuensi negatif jangka panjang untuk masa depan vokasional, kesejahteraan psikologis, kesehatan, dan penerimaan social (Mann, Harmoni, \& Power, 1989).

\section{Simpulan}

Implementasi keputusan karir yang dihadapi antara lain: 1) aspirasi karir yang tidak realistis; 2) merasa rentan karena pengalaman ditolak sebelumnya yang menyebabkan seseorang untuk menahan diri dari mengambil risiko ditolak lagi; 3) efektivitas presentasi diri, biasanya dikaitkan dengan self-esteem yang rendah dan/atau kurangnya keterampilan komunikasi lisan atau tertulis; 4) diskriminasi (sadar atau tidak sadar) di pasar kerja berdasarkan usia, jenis kelamin, ras atau kelas sosial; 5) kurangnya sumber daya keuangan untuk mengejar pelatihan yang tepat; 6) intervensi kesulitan pribadi misalnya dalam bentuk kecelakaan, sakit atau kematian; 
7) sebuah 'karir yang tinggi' mungkin telah tercapai; ini cenderung menjadi umum di pertengahan kehidupan, di mana kesempatan untuk kemajuan dalam bidang karir tertentu menjadi lebih terbatas; dan 8) sebuah keinginan yang tidak realistis untuk 'memperbaiki'; orang mungkin membutuhkan dukungan bahwa dibutuhkan waktu dan usaha untuk membuat perubahan terjadi

Keraguan mengambil keputusan karir tidak saja dikaitkan dengan beragam anteseden . Lewis (2001) berusaha meninjaunya dari kapabilitas remaja dalam mengambil keputusan, dan mengemukakan bahwa kemampuan untuk mengambil keputusan berkembang seiring dengan meningkatnya kebutuhan untuk mengambil keputusan signifikan selama masa remaja

\section{Referensi}

Auger, R. W., Blackhurst, A. E., \& Wahl, K. H. (2005). The development of elementary-aged children's career aspirations and expectations. Professional School Counseling, 322-329.

Bandura, A. (1997). Self-efficacy: The exercise of control. Macmillan.

Bellanca, J. A. (2010). 21st century skills: Rethinking how students learn. Solution Tree Press.

Bentley, T. (2012). Learning beyond the classroom: Education for a changing world. Routledge.

Bubic, A. (2014). Decision making characteristics and decision styles predict adolescents' career choice satisfaction. Current Psychology, 33(4), 515-531.

Bullock- Yowell, E., Leavell, K. A., McConnell, A. E., Rushing, A. D., Andrews, L. M., Campbell, M., \& Osborne, L. K. (2014). Career decision- making intervention with unemployed adults: When good intentions are not effective. Journal of Employment Counseling, 51(1), 16-30.

Creed, P., Prideaux, L.-A., \& Patton, W. (2005). Antecedents and consequences of career decisional states in adolescence. Journal of Vocational Behavior, 67(3), 397-412.

Fisher, T. A., \& Griggs, M. B. (1995). Factors That Influence the Career Development of African-American and Latino Youth. Journal of Vocational Education Research, 20(2), 57-74.

Gati, I., Krausz, M., \& Osipow, S. H. (1996). A taxonomy of difficulties in career decision making. Journal of Counseling Psychology, 43(4), 510.

Gati, I., \& Saka, N. (2001). High school students' career- related decision- making difficulties. Journal of Counseling \& Development, 79(3), 331-340.

Gottfredson, L. S. (1981). Circumscription and compromise: A developmental theory of occupational aspirations. Journal of Counseling Psychology, 28(6), 545.

Gysbers, N C, \& Henderson, P. (1997). Comprehensive guidance programs that work-II. Greensboro, NC: ERIC. CASS publications.

Gysbers, Norman C. (1996). Meeting the career needs of children and adolescents. Journal of Vocational Education Research, 21(4), 87-98.

Helwig, A. A. (1998). Occupational aspirations of a longitudinal sample from second to sixth grade. Journal of Career Development, 24(4), 247-265.

Indonesia, R. (2003). Undang-undang Republik Indonesia nomor 20 tahun 2003 tentang sistem pendidikan nasional. Jakarta: Pemerintah Republik Indonesia.

Mann, L., Harmoni, R., \& Power, C. (1989). Adolescent decision-making: The development of competence. Journal of Adolescence, 12(3), 265-278.

Osawele, R. E., \& Uzairue, L. I. (2013). The relevance of information and communication technologies in libraries services and librarianship profession in the 21th century. International Journal of Basic, Applied and Innovative Research, 2(1), 10-14.

Osipow, S. H. (1999). Assessing career indecision. Journal of Vocational Behavior, 55(1), 147-154.

Seligman, L., Weinstock, L., \& Owings, N. (1988). The role of family dynamics in career development of 5year-olds. Elementary School Guidance \& Counseling.

Super, D. E. (1980). A life-span, life-space approach to career development. Journal of Vocational Behavior, 16(3), 282-298.

Supriatna, M., \& Budiman, N. (2009). Bimbingan karir di SMK. Dalam E-Book.

Tilaar, H. A. R. (1998). Beberapa agenda reformasi pendidikan nasional dalam perspektif abad 21. IndonesiaTera.

Trice, A. D., Hughes, M. A., Odom, C., Woods, K., \& McClellan, N. C. (1995). The origins of children's career aspirations: IV. Testing hypotheses from four theories. The Career Development Quarterly, 43(4), 307-322.

Trilling, B., \& Fadel, C. (2009). 21st Century Skills.: Learning for Life in Our Times. John Wiley \& Sons. 